\title{
Can genetic testing be useful for defining the risk of cancer?
}

\author{
Jerzy Ostrowski ${ }^{1,2}$, Janusz Siedlecki ${ }^{3}$
}

This article is a summary of the opinions of the authors, as presented at the annual conference of the Nowotwory Journal of Oncology, 'Oncological Debates', held in Warszawa, 8-9th April 2016. This work is not a typical review, in that it contains only the viewpoints of the authors, as opposed to any critical review of the literature.

NOWOTWORY J Oncol 2016; 66, 5: 422-426

Key words: genetic testing, cancer, risk

Perhaps contrary to reader's expectations, there is no divergence in the views of the authors concerning the usefulness of genetic testing as a means of determining cancer risk. The only differences lie in their views on the potential for practical use of recognised cancer markers. We both agree that further research is required to seek new markers or surrogate markers. Our perception of the future is hopeful; we anticipate that knowledge of cancer will soon attain a level that permits more precise diagnoses of disease susceptibility and facilitates early detection and an informed choice of the optimal therapy for any given molecular subtype of cancer. We thus decided to compose this article together, without specifically emphasising any of the slight differences in our perspectives.

Genetic variation between any two randomly chosen human individuals is never greater than $0.5 \%$. Such apparently small differences are nevertheless responsible for variability in susceptibility to disease. If we accept the basic premise that the majority of diseases arise from disorders at the molecular and genetic levels, resulting from interactions between genetic disposition and environmental factors, then almost all diseases can be classified into three categories: 1) single-gene disease, 2) polygenic disease, and 3) complex disease (multifactorial, where environmental effects predominate). Underlying the first two categories are gene alterations that increase morbidity. Such gene changes are rare in the population; however, they usually achieve high penetrance. These changes may concern: 1) the loss or acquisition of chromosome(s); 2) rearrangement and loss or acquisition of chromosome fragments (i.e., chromosome aberrations); 3 ) the loss or acquisition of short nucleotide sequences; 4) substitution, insertion or deletion of individual nucleotides within the DNA sequence; and 5) epigenetic changes, not associated with changes in DNA sequence. By contrast, multifactorial diseases, arise as a result of multiple genetic determinants, mainly consisting of single nucleotide polymorphisms (SNPs), which represent more than $90 \%$ of genetic variation and whose incidence in the population is above $1 \%$; this incidence being sufficiently high to make the random appearance of a SNP in the population very likely. These changes are relatively common in the general population and, on account of the discrete selection of particular determinants, can increase susceptibility to disease only by an accumulating effect. In a consequence, the incidence of most disorders is a cumulative result of the "weak" genetic alterations with additive effects and a set of environmental expositions.

An individual's phenotype is comprised of the sum of the cell-specific, developmental-stage-specific, and metabolism-related changes in gene expression, while individual susceptibility to disease is based on genetic variance, which determines the patient's defense and adaptive mechanisms

\footnotetext{
${ }^{1}$ Department of Genetics, Maria Sklodowska-Curie Memorial Cancer Center and Institute of Oncology, Warszawa, Poland ${ }^{2}$ Department of Gastroenterology, Hepatology and Clinical Oncology, Centre of Postgradual Medical Education, Warszawa, Poland ${ }^{3}$ Department of Molecular and Translational Oncology, Maria Sklodowska-Curie Memorial Cancer Center and Institute of Oncology, Warszawa, Poland
} 
against environmental factors, particularly on the molecular level. The main sources of variability in the genetic material of somatic cells are imperfect DNA replication and mutations arising from exposure to physical, chemical, and biological mutagenic agents. In turn, the processes involved in preventing DNA damage have been shaped by evolution and are tightly controlled by mechanisms that prevent excessive genetic diversity. The cell possesses seven primary and approximately fifteen salvage systems for repair of its genetic material; thereby, the vast majority of errors in DNA sequences are corrected. In cases where repair is ineffective, because damage is too severe, cells are effectively eliminated by a process leading to cell death, termed apoptosis, or programmed cell death. Despite the excellent mechanisms in place for regulation of the genome, genomic changes are, nevertheless, periodically duplicated and can lead to increased morbidity in response to pathogenic stimuli; however, such errors are not inherited by offspring, unless they occur in reproductive cells.

Cancer is a classic example of a polygenic disease caused by simultaneous errors in numerous genes. The damage may not necessarily be a mutation (i.e., a change in the DNA sequence), but can be any change which causes the product of the defective gene to either lose, or change (increase or decrease), its ability to fulfil its biological function. Simultaneous failures in many cellular processes lead to a loss of homeostasis. For a cell to be transformed into a cancer cell (i.e., malignant transformation), such changes may occur in a few, or even several tens, of genes. These changes must involve driver genes, since only changes in these genes are capable of eliciting malignant transformation. Changes in passenger genes, which can affect tumour phenotype, do not by themselves induce carcinogenesis. Although there are relatively few driver genes, they are markedly variable dependent on cancer type; hence, driver genes in one type of tumour may be passenger genes in another malignancy and vice versa. In addition, the ability of the same driver genes to induce different types of cancer can vary significantly; for example, mutations in BRCA1 are more effective in inducing transformations leading to breast, than ovarian or prostate, cancers. Although we cannot choose the genomic inheritance we receive from our parents, including all the variants which determine our body's susceptibility and morbidity in response to disease, we can at least identify those genetic changes which make malignant transformations more likely.

Epidemiological studies demonstrate that, according to their type, $5-15 \%$ of cancers are familial. The search for the reasons why certain cancer types are often found in particular families has led to the identification of a group of genes, known as 'susceptibility genes', for specific diseases. Damage to susceptibility genes increases the risk of developing particular types of cancer. Depending on how much they increase the chances of disease, genes are referred to as having high, medium, and low penetrance. Damaged genes with high penetrance may increase the probability of developing a disease to a level approaching unity. This group includes the genes, BRCA1, BRCA2, PTEN, CDKN2A (p16), TP53, and $V H L$, the effects of damage to which on cellular transformation was discovered in the previous century. Genes with medium penetrance increase the chances of disease several fold and include CHEK2, NBS, and PALB2, which, although they belong to the driver gene category, have a somewhat secondary importance in the process of transformation. By contrast, low genetic penetrance is often due to polymorphic variants in detoxification genes, such as GST or NLR.

The majority of cancer predisposition genes exhibit tumour suppressor functions and their mutation leads to the generation of products that alter a broad range of essential cell processes, such as DNA repair, cell cycle regulation, apoptosis, or differentiation. Some of these genes are associated with organ-specific processes; for example, mutations in the SLC25A13, ABCB11, FAP, HMBS, and UROD genes are associated with hepatocyte metabolism which, via the processes leading to liver cirrhosis, increase the risk of developing hepatocellular carcinoma. Only a few genes increase the risk of developing cancer as a result of activating mutations. This group of genes chiefly affect cell signalling, either directly or indirectly.

The development of sporadic tumours (i.e., the vast majority) most often results from 'unfavourable coincidence' and is a slow process. The pre-initiation stage, or exposure to carcinogens, continues throughout a person's life, whereas the initiation period is between 15 and 30 years, the promotion stage a few years, and progression takes place over several months to several years. Furthermore, tumours can consist of several-dozen clones of tumour cells, with differing changes in their genomes. This results in different clinical disease courses and a variable response to treatment, because those types of cancer that are homogeneous from a clinical viewpoint can vary greatly at the molecular level. For this reason, identification of molecular changes may facilitate practical decisions on the type and optimisation of treatment and, in some cases, can even prevent disease.

Regrettably, the biology of cancer is still only partially understood, and the linking of numerous phenomena into a logical sequence of events is frequently based on wishful thinking. In the vast majority of cases, decisions on cancer treatment are based on relatively limited knowledge about the biological processes that have been altered during tumour proliferation. In addition, tumours are treated, to some extent, as homogenous entities. This approach is a major reason underlying the failure of the clinical implementation of biomarkers. We should, therefore, not be asking whether new genetic tests to determine cancer risk can be useful, but rather why does modern medicine use such a limited 
number of genetic tests that could otherwise enable the most precise diagnoses to be made, followed by choice of the most advantageous therapy.

Rates of breast cancer in Poland stand at $12 \%$, while the frequency of somatic $B R C A 1$ gene mutations in breast cancer does not exceed $3 \%$. Germline BRCA1 mutation increases the morbidity risk by up to approximately $80 \%$ throughout the life of a woman, and there is a lower lifetime risk for a woman inheriting a BRCA2 mutation of around $45 \%$. In addition to pathogenic mutations in the $B R C A 1$ and $B R C A 2$ genes, mutations in the medium penetrance $P A L B 2$ and CHEK2 genes play an important role in familial breast cancer. Hence, although it may seem as though the majority of driver genes for breast cancer development are known, our present state of knowledge only allows us to explain approximately $30 \%$ of cases of this type of cancer with a strong genetic contribution, indicating that the absence of mutations in genes known to predispose to disease does not prevent disease morbidity/susceptibility, rather it reduces the likelihood of its occurrence.

Disease diagnosis and classification depend on phenotype imaging. Modern medicine primarily uses anatomic imaging at both macroscopic and microscopic levels, thereby facilitating diagnosis when disease symptoms are initially exhibited, or by chance findings of abnormalities. Only screening can allow a disease to be intentionally detected early in its asymptomatic period; however, screening whole populations is an expensive business and difficult to organise. Increasing the effectiveness of screening, while substantially reducing health care costs, would be possible through medical surveillance of subpopulations of healthy people for whom molecular genetic testing indicates an increased risk of cancer development. Research already permits molecular diagnosis of many single-gene diseases and is also available (unfortunately rarely) for some cases of polygenic disease. In those cancer cases where the 'predisposition genes' are known, genetic testing allows disease risk to be assessed. However, only by the introduction of medical research procedures employing highly efficient technologies, in particular the so-called 'Next Generation Sequencing' (NGS), can there be a chance of creating new and more efficient health care, both at the level of individual patients and that of the whole population.

Genetic association studies constitute the fundamental method of searching for new pathogenic variants. Selecting the appropriate method for an association study depends on the force of impact and incidence of the pathogenic genetic variant under study. When seeking high-impact individual genetic variants, that translate into a high risk of disease development, genetic testing may involve individuals, or families, and the basic study method is large-scale sequencing of either the entire genome, or only the coding sequences of all genes (i.e., exomes), which harbour more than $85 \%$ of pathogenic mutations in 'cancer genes'. When numerous SNPs of low impact are sought, microarray technology, which allows Genome-Wide Association Studies (GWAS) to be performed, is chiefly used. Modern microarrays can analyse several million polymorphisms in a single measurement. Since, at the level of polymorphisms, the magnitudes of associations are generally less than 1.5 , only the use of single study populations consisting of several to tens of thousands of patients and healthy controls will permit a statistically significant association to be demonstrated.

Another problem requiring rapid solution is that of the ability to differentiate between a pathogenic variant associated with predisposition to disease morbidity/susceptibility (mutations in driver genes) and variants in accompanying genes that have no effect on cancer development. Genomic DNA constitutes a huge assembly of static genetic information, variants in which may, but do not necessarily, modify the phenotype of the organism; this feature of 'genetic noise' makes it difficult to identify genuine genotype-phenotype associations.

Simple DNA sequencing is insufficient to explain and map phenotypic disease changes. Moreover, it is not possible to determine epigenetic-environment associations, and there is no known method to correctly predict pathogenicity of genetic variants. Determination of the complete picture of the genetic determinants of disease, including cancer, would require a catalogue of all relevant variants. In the case of oncology, it thus becomes imperative to catalogue all 'cancer genes', which requires sequencing of thousands of genomic DNA samples from tumour cells. This has now become technologically possible. Nevertheless, to ensure genetic and molecular surveillance for increased disease risk, other factors need to be identified, including environmental effects that positively influence health, gene-gene and gene-environment interactions, and inherited epigenetic modifications. This is certainly a difficult task, both in terms of the accessibility of research methodologies and research organisation.

The importance of 'empirical treatment', based on a physician's personal experience, cannot be underestimated but should be supported by treatment using information derived from the molecular taxonomy of disease. Personalisation of cancer treatment should involve adaptation/ /tailoring of therapies based on the molecular subtype of the tumour. Moreover, inter-individual variability in drug metabolism (pharmacogenomics) should also be taken into account. Nonetheless, even the implementation of such obvious procedures can lead to difficulties arising from a lack of fixed algorithms, qualified personnel, funding mechanisms, or regulations; moreover, often there is no evidence for the clinical utility of new biomarkers.

Genetic and molecular descriptions of disease phenotypes require that physicians and biologists collaborate, 
both groups providing/delivering clinical and experimental data, along with their expertise in the fields they represent, and taking advantage of the tools of computational biology. Such collaborations should lay the foundations for integration of genomics into clinical oncology. It is only when difficulties in methodical interpretation are overcome in the performance of molecular and genome wide analysis, that medical progress can be clearly accelerated. However, until such time as physicians see direct benefits of molecular genetic studies for clinical practice, they will remain as mere molecular research studies, without any practical verification, with only biologists and biotechnologists involved and no active participation of physicians. For this reason, teaching of genetics and molecular biology should be introduced into a much wider range of medical undergraduate and postgraduate education. Without such knowledge physicians are helpless when confronted with test results obtained by modern techniques of nucleic acid sequencing. In this way, it will also be possible to extend the collaboration of the medical fraternity with the developing field of molecular medicine.

A genetic counselling network has been established in Poland. The majority of centres offer genetic testing, where usually one or several cancer predisposition genes are assessed; however, only very few provide comprehensive information on morbidity/susceptibility risks that include oncology surveillance of carriers of mutated genes and their families. Genetic testing should be preceded by an analysis of the family pedigree by a clinical geneticist, which will allow patients to be assigned to specific risk groups, thereby guiding the choice of possible genetic testing. Unfortunately, the majority of genetic counselling services (which usually having a profit-making ethos) undertake genetic testing without those involved having a prior consultation with a clinical geneticist. In these cases, the outcomes obtained are so vague and broad that they do not meet the expectations of those tested. Advice given by genetic counsellors should be informative, but not provided as commands or in a dictatorial manner. In addition to providing direct information about genetic burden, the advice should include the following information: 1 ) whether it is possible to, and if so, how to, prevent the onset of disease; 2) how to detect the disease at an early stage of development; and 3) how to limit the consequences of disease. The patient should also be advised about informing other members of their family of their risk of developing the disease and control measures to prevent this from occurring. Under no circumstances should test results be used for any purposes other than health. The patient and their family should be provided with psycho-oncology counselling. Regrettably, these legitimate demands are rarely fully met, primarily because of a shortage of clinical geneticists and psychooncology counsellors in the Polish health care system. There are private companies in the Polish medical market that offer a plethora of genetic testing, usually only for the so-called 'cancer genes'.

Although genetic counselling (while imperfect) is a positive contributing factor in developing a surveillance programme for those vulnerable to developing familial cancers, actual establishment of genetic surveillance for rare cancers remains an unsolved problem. There are no rules nor procedures regarding studies that evaluate the effect of environmental factors on the human body over a lifetime; therefore, the early diagnosis of selected types of cancer (such as breast, colorectal, cervix, or prostate cancer) still represents the key function of screening programs.

\section{Conflict of interest: none declared}

\author{
Prof. Jerzy Ostrowski, MD, PhD \\ Department of Genetics \\ Maria Sklodowska-Curie Memorial Cancer Center \\ and Institute of Oncology \\ Roentgena 5, 02-781 Warszawa \\ e-mail:jostrow@warman.com.pl
}

Received \& Accepted: 11 Jul 2016

Based on the presentation at the IV Annual Conference of the Nowotwory Journal of Oncology, 'Oncological Debates', held in Warszawa, 8-9th April 2016

\section{References}

The authors first list their own publications, upon which this article is based:

1. Ostrowski J. Era medycyny molekularnej; Genetyczno-molekularne podstawy rozwoju nowotworu; Genetyka molekularna chorób układu pokarmowego. In: Genetyka molekularna w chorobach wewnętrznych, A. Ciechanowicz i F. Kokot (eds.). Warszawa: PZWL, 2009.

2. Ostrowski J, Wyrwicz LS. Integrating genomics, proteomics and bioinformatics in translational studies of molecular medicine. Expert Rev Mol Diagn 2009; 9: 623-630.

3. Siedlecki JA. Molekularne mechanizmy kancerogenezy. In: Kompendium chirurgii onkologicznej, A. Jeziorski, P. Rutkowski (eds.). Gdańsk: Via Medica, 2014.

4. Siedlecki JA. Biologia molekularna nowotworów. In: Podstawy Onkologii Klinicznej, J. Meder (ed.), Warszawa: CMKP, 2011.

5. Siedlecki JA. Molekularne mechanizmy warunkujące powstanie raka trzonu macicy. In: Nowotwory trzonu macicy, M. Bidziński (ed.). Warszawa: CMKP, 2011.

6. Siedlecki JA. Choroby nowotworowe. In: Biologia molekularna w medycynie: elementy genetyki klinicznej, J. Bal (ed.). Warszawa: Wydawnictwo Naukowe PWN, 2011.

7. Siedlecki JA. Molekularne czynniki prognostyczne i predykcyjne $w$ raku jelita grubego. In: Rakjelita grubego, A. Deptała, M.Z. Wojtukiewicz (ed.). Poznań: Termedia Wydawnictwa Medyczne, 2012.

8. Siedlecki JA, Kowalewska M. Molekularna patogeneza nowotworów złośliwych. In: Zarys ginekologii onkologicznej, J. Markowska, R. Mądry (eds.). Poznań: Termedia Wydawnictwa Medyczne, 2015.

9. Siedlecki JA. Molekularne podłoże raka wątrobowokomórkowego. In: Rak wątrobowokomórkowy, M. Krawczyk (ed.). Warszawa PZWL, 2015.

Below are selected articles from other publications, containing opinions consistent with the views of the authors:

1. Alberts B, Johnson A, Lewis J et al. P. Molecular biology of the cell. New York \& London: Garland Publ, 2002.

2. Andre F, McShane LM, Michiels $S$ et al. Biomarker studies: a call for a comprehensive biomarker study registry. Nat Rev Clin Oncol 2011; 8: $171-176$. 
3. Fisher R, Puszta L, Swanton C. Cancer heterogeneity: implications for targeted therapeutics. Br J Cancer 2013; 108: 479-485.

4. Garraway LA, Lander ES. Lessons from the cancer genome. Cell 2013 ; 153: 17-37.

5. Garrido-Laguna I, Hidalgo M, Kurzrock R. The inverted pyramid of biomarker-driven trials. Nat Rev Clin Oncol 2011; 8: 562-566.

6. Goel A, Boland CR. Epigenetics of colorectal cancer. Gastroenterology 2012; 143: 1442-1460.

7. de Gramont A, Watson S, Ellis LM et al. Pragmatic issues in biomarker evaluation for targeted therapies in cancer. Nat Rev Clin Oncol 2015; 12: 197-212.

8. Hanahan D, Weinberg RA. Hallmarks of cancer: the next generation. Cell 2010; 144: 646-674.
9. Liu L, Yick-Lun So A, Fan JB. Analysis of cancer genomes through microarrays and next generation sequencing. Trans/ Cancer Res 2015; 4: 212-218.

10. Meric-Bernstam F, Mills GB. Overcoming implementation challenges of personalized cancer therapy. Nat Rev Clin Oncol 2012; 9: 542$-548$.

11. Mwenifumbo JC, Marra MA. Cancer genome-sequencing study design. Nat Rev Gen 2013; 14: 321-332.

12. Tomasetti C, Vogelstein B. Variation in cancer risk among tissues can be explained by the number of stem cell divisions. Science 2015; 347 : 78-81.

13. Vogelstein B, Papadopoulos N, Velculescu VE et al. Cancer genome landscapes. Science 2013; 339: 1546-1558. 